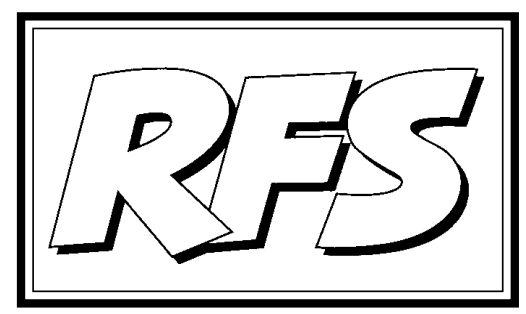

Revista de Fomento Social, 56 (2001), 695-705

\title{
El fenómeno de la inmigración en España
}

J oaquim PONS, SJ

\section{Introducción}

España es un estado plurinacional con diversidad de culturas. A través de los flujos migratorios internos de los años 50-60, estas culturas se vieron forzadas a convivir en un mismo espacio ciudadano. Este proceso de integración social no se hizo sin tensiones. Actualmente en algunas regiones de España, como es el caso de Cataluña, más del $70 \%$ de la población tienen familiares de fuera de Cataluña (resto de España).

Hasta los años 80, España fue un país fundamentalmente emisor de emigrantes. Muchos españoles tuvieron que dejar su tierra para emigrar a Latinoamérica y a diversos países de Europa Central, entre ellos, Francia,

1 Centre Immigrants Sant Pau (Mataró, Barcelona). Ponencia presentada en la reunión del grupo EUROJESS 2001. Véase crónica de dicha reunión en este mismo número. 
Suiza y Alemania son un buen ejemplo² ${ }^{2}$ En nuestros días, aún viven fuera de nuestras fronteras más de 2 millones de españoles.

En 1974, con la crisis del petróleo, muchos países de Europa Central empezaron a cerrar sus fronteras. Las leyes de admisión de extranjeros se endurecieron de tal forma que muchos de ellos se quedaron en la frontera española. De esta forma se incrementaba el número de inmigrantes no comunitarios que ya habían empezado a llegar a finales de los años 60 . Al acabar el año 2000, el porcentaje de residentes extranjeros era del 2,2\%, de los cuales un $1,4 \%$ proceden de países del Sur.

La llegada de inmigrantes no comunitarios se ha ido generando a lo largo de estos últimos 35 años. Aquellas personas que llegaron hace 20 ó 30 años, ya no las podemos considerar emigrantes económicos, son personas que se han ido arraigando a nuestra tierra. Estos primeros flujos fueron poco significativos sobre el total de la inmigración actual en España. El debate social en torno a la inmigración se ha generado en la sociedad española a partir de los años 90, cuando se ha ido organizando de forma regular o irregular (mafias) su llegada.

Estas tres caras de la emigración en España muestran la evolución socioeconómica de nuestro país durante estos últimos 50 años y la lógica natural de los procesos migratorios. España fué un país de emigración y, en nuestros días la prosperidad económica lo ha convertido en un nuevo país receptor de flujos migratorios. Un cambio en las dinámicas sociales, quela población local necesita su tiempo para irlo asumiendo. Nuestra historia reciente debiera ayudarnos a ponernos en la piel de tantos hombres y mujeres que nos llegan con la misma esperanza que un día tantos españoles pusieron al tener que emigrar.

\section{Una aproximación estadística}

Según datos del Ministerio del Interior (Comisaría General de Extranjería), a 31 de diciembre de 2000 la población total extranjera residente en el Estado Español era de 895.720 personas, lo que representa un 2,2\% de la población española. Los residentes procedentes de la Unión Europea, Estados Unidos y J apón representan un 36\% (323.053 residentes). El 64\% restante correspon-

2 Según Registro de Matrícula de residentes en los Consulados Españoles a 31 de diciembre de 1996, el número de residentes españoles en Francia era de 296.036, en Suiza de 168.896 y en Alemania 152.405 personas. 
de a la población inmigrada procedente de países del Sur y Este de Europa (572.667 residentes).

Para tener un panorama de la inmigración extranjera en España, presento la siguiente distribución por áreas geográficas y países más representativos en cuanto a número de población ${ }^{3}$ :

Unión Europea

Reino Unido

Alemania

Francia

Resto Europa

Rumanía

Polonia

Rusia

Norte de África

Marruecos

Argelia

Resto de África

Senegal

Gambia

Latinoamérica

Ecuador

Perú

República Dominicana

Resto de América

EE.UU

Asia y Oceanía

China

Filipinas

Pakistán

India
11.051

8.840

13.714

28.693

13.160

7.843

7.813

$306.203(34,2 \%)$

60.575

42.316

10.983

8.143

4.835

199.782

$45.897(5,1 \%)$

$185.066(20,7 \%)$

30.878

27.888

26.481

$15.152(1,7 \%)$

$73.347(8,2 \%)$

$1.017(0,1 \%)$

$53.800(6,0 \%)$

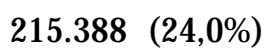

$215.388(24,0 \%)$

A pátridas y no consta 
Dos puntos me gustaría subrayar a partir de estas cifras: queda claro que el principal colectivo de inmigrantes Ilega de Marruecos, supone un $22,3 \%$ del total de extranjeros residentes en España, a gran distancia le siguen dos países de la Unión Europea: Reino Unido (8,3\%) y Alemania (6,8\%). El segundo punto nos lleva a deshacer el tó pico quese da últimamente entre la población española al hablar de "Ilegada masiva de inmigrantes". Como he indicado anteriormente, la población extracomunitaria (excepto USA y J apón) actual no supera el $1,4 \%$ de la población española, un porcentaje muy inferior al de otros países de la Unión Europea.

\section{Integración social y política migratoria del gobierno}

Hablar de las posibles motivaciones para una "integración" o "no-integración" de los inmigrantes en la nueva sociedad de acogida melleva, de entrada, a recordar que la integración social de los inmigrantes es un fenómeno que apunta en dos direcciones 0 , si se quiere, que obliga tanto al inmigrante que llega como al ciudadano que acoge.

En cada país, los procesos de integración quedan determinados por el marco jurídico que enfoca la política migratoria de cada gobierno. Si bien las grandes directivas vienen determinadas por la política migratoria de la Unión Europea (Acuerdos de Schengen, tratados de Maastritch y Amsterdam y cumbres de Tampere y Niza), aún así, a cada gobierno le queda margen de maniobra para mostrar su voluntad política de integración ante el reto social que supone el fenómeno de la inmigración.

El triple enfoque que presento, pienso que da pistas de por donde va la voluntad política del actual gobierno de cara a facilitar la integración social de los inmigrantes no comunitarios.

\subsection{Inmigrantes en situación regular: una integración posible}

El actual marco jurídico español ${ }^{4}$ hace una lectura parcial de lo que acabamos de definir como integración social, legisla el acceso a los bienes públicos por parte de los inmigrantes residentes (escuela, sanidad, trabajo,

4 Ley Orgánica 8/ 2000 sobre derechos y libertades de los extranjeros en España y su integración social de 12 de diciembre (Ley de Extranjería) y Programa global de regulación y coordinación de la extranjería y la inmigración en España (Programa GRECO) para el período 2000-2004. 
vivienda) pero pasa muy superficialmente por aquellas líneas que debieran definir una cultura de la recepción por parte de los ciudadanos que acogen. En este sentido deberían de darse pautas mucho más concretas en la sensibilización social de la población local respecto a la inmigración como un fenómeno positivo para nuestro país o potenciar una educación en todos los ámbitos que sensibilizase contra el racismo y la xenofobia.

La actual Ley de Extranjería marca una diferencia muy nítida entre los extranjeros residentes y aquellos que se encuentran en situación irregular.

2.2. "Criminalización" de los inmigrantes en situación irregular: cuando la integración deviene un sueño imposible

La nueva Ley de Extranjería "criminaliza" la presencia de los inmigrantes irregulares en territorio español. Derechos fundamentales como los de reunión y asociación, libertad de sindicación y derecho a la huelga, desaparecen. La única salida que les queda es permanecer en el Estado español de forma irregular y, si no son expulsados durante este tiempo, a los 5 años podrían regularizar su situación si demostrasen que disponen de medios económicos para sustentarse. Por otro lado, las causas de expulsión se endurecen y sigue dándose la posibilidad del internamiento preventivo del extranjero inmerso en un proceso de expulsión, éste puedellegar a los 40 días de internamiento.

La nueva ley mantiene, al menos, el derecho a la sanidad pública básica de todos los extranjeros, independientemente de su situación jurídica. También la educación pública hasta los 16 años es obligatoria para todos los menores, incluidos los que se encuentren en situación irregular.

2.3. Favorecer la inmigración temporal: evitar la factura de la integración familiar

Como veremos, dos de las características significativas del perfil de la inmigración en España es la presencia de la mujer y la de los menores de 16 años. Este perfil, acentúa en el fenómeno inmigratorio la dimensión familiar sobre la individual. Cuando un familia deja su tierra no lo hace pensando en una vuelta inmediata. Vemos, por tanto, que la inmigración en España es un fenómeno que busca la permanencia sobre la temporalidad. La experiencia migratoria de otros países de la Unión Europea nos lo confirma. 
En 1997, el 42\% de los irregulares llevaba viviendo en España entre 6 y 10 años. Es razonable pensar que durante estos años algún trabajo habían conseguido para sustentarse. No olvidemos que la gran mayoría de los inmigrantes no comunitarios residentes han pasado también por la experiencia de la irregularidad. De ahí vienen nuestras contradicciones sociales y la confusión en la que se encuentra la política española de inmigración: las regularizaciones extraordinarias desmienten el perfil temporal que el gobierno quiere dar a la inmigración.

\title{
2.4. ¿Voluntad política de integración?: a modo de conclusión
}

H. B. Entzinger, sociólogo holandés, 11 años atrás hacía el siguiente análisis de las políticas de migración europeas:

\begin{abstract}
“... no se ha de concluir automáticamente que los inmigrantes en situación irregular sean siempre indeseados. Quizás desde el punto de vista legal no debieran existir, pero desde del punto de vista económico podrían desempeñar funciones cruciales. Por esta razón, las autoridades públicas toleran con frecuencia su presencia en el país. Incluso en estas condiciones es bastante improbable que el país de acogida se incline a elaborar una forma, cualquiera que sea, de política de integración en a favor de ellos".
\end{abstract}

Debiéramos preguntarnos si este análisis no anticipaba la situación actual que se vive en el Estado Español. No olvidemos que nuestra economía de mercado precisa de una "reserva permanente de mano de obra". Si la oferta de trabajo no se puede cubrir por medio decontratos temporales, se hará uso dela presencia de los inmigrantes en situación irregular. España es uno delos países donde la economía sumergida tiene un mayor porcentaje respecto al PIB: según un Informe de la Comisión Europea (1998) éste podría ser del orden del $23 \%$.

Antes de la última regularización extraordinaria (julio 2000), se calcula que en España habían cerca de 300.000 inmigrantes en situación irregular, entre ellos había familias completas. El miedo, la soledad, la desconfianza difícilmente motivan la integración de estas personas en la sociedad. Son personas que se encierran en sus colectivos, buscando la protección que la "sociedad de acogida" les niega: de esta forma se cae en dinámicas de "guetización". Como acabamos de ver, muchas de estas personas han pasado de 6 a 10 años en situación irregular, tiempo suficiente para iniciar procesos de degradación social en muchos barrios donde se concentra esta población, aumentando las bolsas de pobreza de al gunas ciudades y potenciando los sentimientos de racismo y xenofobia en la población local. ¿Cuales pueden ser la motiva- 
ciones de integración social para estas personas "sin-derechos"?

Aun en el mejor de los casos nos encontramos con situaciones absurdas: no es coherente que los niños, cuyos padres están en situación irregular, vayan a la escuela obligatoria hasta los 16 años y después no puedan continuar su formación laboral por estar en situación irregular. ¿Para quélos hemos formado durante estos años? ¿Cómo podemos facilitar la integración social de estos jóvenes si les negamos la formación laboral? ¿Qué salida les damos?

Quizás debiéramos preguntarnos si con la potenciación de la inmigración temporal, lo que busca la actual política migratoria del go bierno es ahorrarse el coste social de la integración familiar (escuelas, sanidad,...). Según la filosofía utilitarista: se quiere una mano de obra barata, de "un solo uso", 69 meses de trabajo y vuelta a casa. ¿Hasta cuándo?

\section{Algunos aspectos significativos del perfil de la inmigración en España}

3.1. La visión clasista del inmigrante económico

Ante el fenómeno de la inmigración económica es habitual escuchar, en muchos ámbitos de la sociedad española un discurso fundamentado en términos economicistas, configurando un discurso clasista, que obedece a un asunto entre ricos y pobres. Generalmente sólo visualizamos como inmigrantes económicos a los colectivos más precarizados, los que provienen de países del Sur. Pero debiéramos tener presente que el segundo colectivo de inmigrantes extranjeros en España es el de los británicos y que el total de los inmigrantes de países del Norte supone, como hemos visto, el nada despreciable porcentaje del $36 \%$ de la inmigración que llega a España.

Desde esta perspectiva se da una clara distinción entre aquellos que vienen a "producir" Estado de bienestar (deportistas, altos ejecutivos de multinacionales,...) y aquellos que, supuestamente, vienen a "consumirlo" (trabajadores). Debiéramos de ser más objetivos y tener presente las últimas cifras sobre la aportación económica de los trabajadores extranjeros a las arcas del Estado: ingresaron 335.000 millones de pesetas (201.339 euros) en concepto de cotizaciones a la seguridad social y el Estado invirtió en servicios a esta población 148.000 millones de pesetas (88.950 euros); un balance totalmente positivo para el Estado.

El fenómeno social que representa la presencia de tantos miles de inmi- 
grantes en situación irregular potencia la precarización de estos colectivos y refuerza entre la población local la imagen estereotipada de personas problemáticas. Esta imagen se generaliza fácilmente al total del colectivo, incluidos aquellos que se encuentran en situación legal y se acaba afirmando que los inmigrantes económicos son un problema social.

\subsection{El proceso de feminización de la inmigración}

A lo largo de la década de los 90 se ha dado un claro proceso de feminización de la inmigración que llega al país. Si bien hay inmigraciones tradicionalmente femeninas, como es el caso de las dominicanas, filipinas y peruanas, estos últimos años ha ido en aumento el proceso de feminización de la inmigración marroquí, principal colectivo de extranjeros en España.

Respecto a este último colectivo, las mujeres inmigrantes más antiguas respondían a una edad más avanzada y se dedicaban en exclusiva al trabajo en el hogar: eran mujeres reagrupadas por sus maridos. Actualmente las mujeres que llegan son mucho más jóvenes y trabajan como asalariadas en el trabajo doméstico. La mujer pasa a ser protagonista del proyecto migratorio y en algunos casos es ella la que reagrupa a la familia. En cuanto a las condiciones laborales, se produce la misma discriminación de género que con la mujer española.

Uno de los tópicos asumidos en ciertos foros de la inmigración es el de que la mayoría de las mujeres inmigrantes no trabajan y son mantenidas por sus maridos. Los datos estadísticos actuales contradicen esta creencia. En el año 1999 prácticamente la mitad de los inmigrantes no comunitarios residentes en territorio español eran mujeres (47\%). En España, la mayor concentración de empleo femenino inmigrante se da en Madrid, que reúne el $50 \%$ de las mujeres con permiso de trabajo, y en segundo lugar se halla Cataluña con el $24 \%$.

El porcentaje de inmigración de mujeres u hombres depende del país de origen. Así por ejemplo, las mujeres suponen el $65 \%$ de la inmigración de Latinoamérica. En contraste, la inmigración africana está más masculinizada, si bien el porcentaje de mujeres está subiendo (33\%). La inmigración asiática femenina representa el $47 \%$. 


\subsection{El aumento de la presencia de menores de 16 años}

Como he indicado anteriormente, la presencia de los menores de edad es un indicador de la permanencia en territorio español de los inmigrantes que van llegando. El proceso de reagrupación familiar ha permitido que se vaya consolidando la segunda generación, los hijos de los inmigrantes. En 1999, de cada 100 residentes extranjeros, 10,7 eran menores de 16 años. El proceso de integración social de la población inmigrante se juega de forma determinante en los hijos de los inmigrantes. En este segmento de la población es donde se da de una forma más clara el choque cultural que supone todo proceso de integración social. Los padres, preocupados por el trabajo y la marcha de la casa, no viven de forma tan determinante este choque de culturas. Los hijos, en la escuela viven unos valores, hablan una lengua, se introducen a una cultura que, en algunos casos, les es totalmente nueva. Cuando llegan a sus casas viven otras coordenadas socioculturales que deben de saber ir integrando en su vida. No siempre se acierta en este proceso de integración, y de ahí a las patologías sociales hay un paso: absentismo escolar, niños de la calle, delincuencia juvenil,...

Los porcentajes más significativos de menores de 16 años sobre el total de los colectivos respectivos supone, en el caso de los gambianos, el 30,9\%; en el de los marroquíes, el 21,8\%; en el de los pakistaníes, el 17,9\%.

\section{Algunas lógicas de comportamiento social ante la presencia de los inmigrantes}

Según el lugar que ocupa el ciudadano en la sociedad española, su discurso, su manera de situarse ante la inmigración, varía:

\subsection{La lógica utilitarista: cuando se "utiliza" al inmigrante}

Hay una lógica que se manifiesta en el discurso de algunos políticos y se fundamenta en una filosofía utilitarista que habla de la necesidad de mano de obra extranjera pero con el mínimo coste social para el país. Nos encontramos con la figura del inmigrante-objeto, la cosificación del fenómeno migratorio. El inmigrante se convierte en "algo" que "nos sirve" para cubrir nuestras necesidades: garantizar las cotizaciones a la seguridad social y de esta forma asegurar nuestras futuras pensiones; garantizar el crecimiento de población para que algunas de nuestras escuelas de educación infantil no 
cierren; cubrir aquellos lugares de trabajo que nosotros ya no nos dignamos ocupar y cubrir las filas de un ejército que los mismos nacionales abandonan. Esta lógica tiende a descuidar los derechos de estos trabajadores.

4.2. La lógica nacional proteccionista: cuando el inmigrante deviene un competidor

Se da en los barrios periféricos que acogieron las anteriores oleadas de inmigración interna de los años 50-60. Con frecuenciala noción de convivencia se entendía como la subordinación a la ley por parte de todos, sin excepciones. Por consiguiente, la diversidad cultural se habría de regular con una ley (consuetudinaria) que nos identifique a todos por igual. Tal identificación con "la normalidad" ("porque siempre se ha hecho así") convierte la diferencia en anomalía. La gente de estos barrios tiene muy claro lo que es o ha sido "la normalidad", "eso ha sido así toda la vida". Los nuevos vecinos, diferentes en sus manifestaciones culturales, rompen esta normalidad.

Por tanto, la posible diversidad se ha de regular desde de la uniformidad: "son ellos los que se han de integrar", coincidirán. Este modelo de uniformidad nos lleva a identificarnos con el concepto de nación "de toda la vida" ("todos somos iguales"). De ahí que la diferencia se vea como una anomalía que conviene erradicar. En este contexto muchos vecinos entienden las minorías como un peligro, una amenaza, que está latente, pero que intentará imponerse en el momento en que la situación les sea más favorable. De esta manera la diversidad de culturas se ve como diversidad de opciones que puede llevar a conflictos. Se cae fácilmente en actitudes discriminatorias.

Esta lógica nacional proteccionista es propia de barrios donde muchos de los autóctonos viven en situaciones de precariedad, de dependencia de los servicios sociales, que ahora hay que compartir con los foráneos. Se trata de exigir la propia protección, y se genera una crisis de identidad que excluye a los inmigrantes reduciendo, en consecuencia, el campo del discurso solidario y tolerante. Yo diría que esta es la lógica más extendida, consciente o inconscientemente, en la sociedad española.

\subsection{La lógica paternalista: cuando se "marginaliza" al inmigrante}

Como reacción a una lógica nacional proteccionista se pueden dar planteamientos que apunten a un universalismo simplista, ingenuo, para proteger el 
principio de igualdad entre las personas: "Todos somos hijos de Dios". Se puede caer entonces en una lógica paternalista que tiende a incluir al inmigrante en el campo de la marginación. El inmigrante se convierte en objeto de protección y ayuda, aunque él no lo pida. No se les considera ciudadanos capaces de derechos y deberes y de organizarse la vida. Con toda la buena volundad, se les condena a ser usuarios de los servicios sociales. No habría que olvidar que los inmigrantes que nos llegan son la nueva clase trabajadora, que en muchos sectores productivos sustituyen a los trabajadores que nos llegaron en los procesos migratorios internos de los años 50-60.

Llegados a este punto, convendría dar un toque de alerta a ciertas organizaciones no gubernamentales porque a menudo acentúan un discurso sobre la reivindicación de los derechos de los inmigrantes, y es verdad que hay que hacerlo por "imperativo moral", pero en la medida en que los inmigrantes se van integrando en la sociedad (empleo estable, piso propio, seguridad social...) debemos ir acentuando el discurso de sus obligaciones. Aun cuando lleguen hasta el derecho al voto, no llegarán a ser plenamente ciudadanos y ciudadanas. Sólo así podrán ser tratados como verdaderos conciudadanos, sujetos de derechos y de obligaciones.

4.4. La lógica solidaria: cuando con el inmigrante construimos un nuevo "nosotros"

Se trata de una dinámica social que nace del encuentro, del conocimiento mutuo entre inmigrantes y sociedad de acogida. Esta lógica nos lleva a caminar juntos para construir una nueva realidad social, una nueva ciudadanía. Lejos está el paternalismo, pues el inmigrante aquí tiene su protagonismo. Esta lógica solidaria debe partir de lo que "somos" unos y otros, sin renunciar a nuestra propia identidad y cultura: ésta debiera de ser la postura que mejor pueda mostrar nuestra solidaridad con nuestros nuevos vecinos. Entonces inmigrantes y nacionales se esfuerzan en un proceso de crecimiento, que apunta a algo nuevo, no sin tensiones ni crisis, que bien enfocadas ayudarán a construir un nuevo "nosotros". Estees el reto, no el problema, que la inmigración nos plantea. 